\title{
The Potential Utilization of Blockchain Technology
}

\author{
Untung Rahardja ${ }^{1}$, Ninda Lutfiani ${ }^{2}$, Qurotul Aini ${ }^{3}$, Isabella Yaumil Annisa ${ }^{4}$ \\ Universiti Teknologi Malaysia ${ }^{1,3}$, University of Raharja, Indonesia ${ }^{2,4}$ \\ Sultan Ibrahim Chancellery Building, Jalan Iman, 81310 Skudai, Johor ${ }^{1,3}$ \\ JI. Jenderal Sudirman No.40, RT.002/RW.006, Cikokol, Kec. Tangerang, Kota Tangerang, \\ Banten $1511^{2,4}$

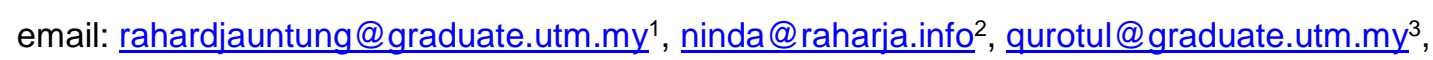 \\ isabella@raharja.info 4 \\ Rahardja, U. ., Lutfiani, N., Aini, Q., \& Yaumil Annisa, . I. (2021). The Potential Utilization of \\ Blockchain Technology. Blockchain Frontier Technology, 1(01). 01-11 \\ Retrieved from \\ DOI: https://journal.pandawan.id/b-front/article/view/6
}

\begin{abstract}
The application of blockchain innovation in E-commerce has a benefit. Add a space be the need for closeness sense in carrying out the transaction process in a security framework is required to preserve the privacy of information. One of the technological marvels is a Blockchain. The application of Blockchain innovation is to supply security for certificate security within the computerized period 4.0 so as not to control by unreliable parties. By utilizing the strategy of issue detailing, inquire about the plan, information, information preparing \& introduction, examination \& research reports and investigate strategies seven writing ponders. The application of blockchain innovation in an E-commerce service may be a need for closeness sense in carrying out the exchange handle a security framework is required to preserve information secrecy. Numerous things are valuable in Blockchain innovation, counting observing monetary resources, wellbeing records, character, and planning the supply chain. However, many proposals lack criticism and have static thinking. So that it fails to get the main benefits of the blockchain.
\end{abstract}

Keyword: Blockchain, Note Technology.

\section{Introduction}

Many uses in the blockchain.Among others, to track financial assets, manage identities, health records, and coordinate supply chains. However, many have suffered from a lack of criticism and a static system of thought that has failed them to take advantage of the main benefits of the blockchain itself and its record disadvantages [1].

At its simplest level, Blockchain is a new way of building databases where the database is placed under the collective control of multiple parties instead of a central authority. Because of this, the first question to ask when assessing how to use blockchain is whether it can be implemented satisfactorily by regular centralized databases such as Potgres, MySQL, SQL Server, and Oracle [2], [3]. if "yes" nothing value using blockchain. Then it is still a young and immature technology. whereas programs like MySQL and Oracle had evolved over the decades before them [4].

Although there are some applications for the ideal blockchain architecture at its core, this paper provides a framework for evaluating the viability of blockchain use[5]. From 4 different angles [6]. First, we focus on the reason for blockchain, basic disintermediation data which can 
be defined about the ability for multiple parties, namely by sharing one database without putting the database under one control. a checklist is provided to assess if this disintermediation helps.

Then, looking at the two keys to blockchain luck, when compared to databases performance and confidentiality, we then outline 4 common types of uses for which the tradeoffs tend to like the blockchain architecture. and in the end, we looked at 3 software exams. we use it in production to see what conclusions can be drawn [7].

It's important to explain this specially written with "permissioned" in mind. that is, on a different basis from the blockchain without the basis of cryptocurrencies such as Bitcoin and Ethereum, even though they share a lot of technical characteristics. Unlicensed blockchain like bitcoin requires an economy with consensus mechanisms such as proof-of-work or proof of ownership to govern, as well as the processes that anyone who makes investment needs will be able to participate [8]. This mechanism provides the main benefit financially to try to undermine the function of the chain. However, as a result, the need to use crypto tokens that allows attracts suspicion from the government and financial institutions and tends to be volatile in value.

\section{Literature Review}

\subsection{Database}

The innovation that will be utilized with shared databases is called Blockchain. The primary step to require is to step in and choose whether to utilize it knowing why to utilize a database, which can be characterized as an organized store of data [9]. The store can be a database of territorial relations and contain one or more tables like a spreadsheet, or it can be of the trendier NoSQL variety, which works more like a word reference framework[10].

For case, a resource budgetary record is spoken to as a database table. Where each line speaks to and sends a sort of resource that's possessed by a specific substance. Each push has 3 columns containing (1) Proprietor identifier, such as account number; (2) An identity for resource sorts, such as USD or AAPL; and (3) Add up to resources held by the owner.

Database adjustment includes an arrangement of changes to the database, which must be acknowledged or rejected as an entirety. Within the case of record resources, an installment from one client to another includes an exchange that subtracts the sum from one line and includes the other [11].

\subsection{Multiple Writers}

In order for the Blockchain service to be recommended, the database must have multiple writers, i.e., more than one entity, and must produce database modification transactions. it is to compile a list of author identities.

In numerous cases, creators will moreover work "hubs" that store duplicates of the database record, handle exchanges locally, and pass exchanges to other hubs in a peer-to-peer way [12]. Be that as it may, exchanges are too made by clients who are not running the hub. For case, most installment frameworks are overseen collectively by a little bunch of banks but have millions of conclusion clients on portable gadgets who as it were communicate with their claim bank systems [13].

\subsection{A Lack Of Trust}

Blockchain is a technology for databases that have multiple authors, and there is also some degree of distrust among author entities for being given a database [14].

Maybe, this doubt emerges as it were between organizations, such as a bank exchanging in a showcase or a company included within the supply chain. It might moreover be between departments inside one organization, for a case, between operations of organizations different countries. It implies doubt within the setting of a database that one client does not let another client alter their database passages [15]. Moreover, one client will not acknowledge as genuine what other clients report since each has political or financial seriously differences [16].

\subsection{Disintermediation}


The issue, characterized so distant is how to function a database that has numerous mistakes. This issue has as of now happened and a well-known arrangement: tristed mediator, which all creators can believe even in case they don't totally believe each other. The world is filled with databases such as bank account records. The bank controls the database and guarantees that each exchange is approved and verified by the client whose reserves alter. It doesn't matter how neighborly the client inquires, the bank will not let alter the basic information straightforwardly [17].

This blockchain technology can not only be implemented in the financial sector, but can also be implemented in various fields, one of which is education. With the development of the times, education has become very important, so many people are competing to complete their education. Blockchain technology is very useful in various fields as shown in Figure 1.1

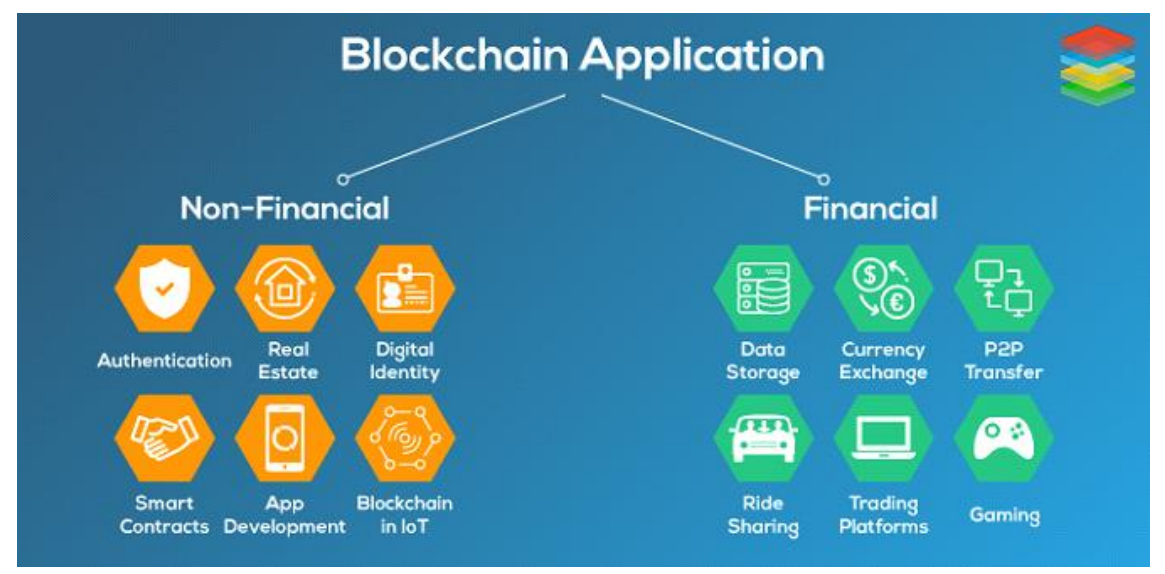

Figure 1. Application of blockchain technology

Blockchain dispenses with the requirements for a trusted middle person by empowering coordinate alteration of the database with numerous skeptical creators. no overseer center is required to confirm exchanges and verify their sources. Ideally, the exchange definition is expanded to incorporate confirmation of specialist and approval. Future exchanges can be freely confirmed and prepared by each hub and keep up a duplicate of the database [18] [19].

A sensible address is, what application requires disintermediation? Does it matter on the off chance that you've got a central party that keeps up to preserve a definitive database and acts as an exchange door protect? The reply, perhaps there are great reasons to select blockchain-based information on a trusted mediator [20]. These incorporate having lower costs, quicker workflows, programmed compromise, unused directions, or the failure to discover a reasonable intermediary.

\subsection{Transaction Interaction}

As explained, the blockchain creates a database that is shared by multiple authors who can modify the database directly but cannot completely trust the respective modifiers. The blockchain becomes stronger when there are multiple interactions between the author's multiple transactions [21].

Exchange interaction implies that operations performed by diverse creators within the database are forbidden. In case, Alice sends a few cash to Weave, and Weave sends it to Charlie. In that case, Bob's exchanges depend on Alice's, and there's no way to confirm Bob's exchanges without checking Alice to begin with. Because of this reliance, exchanges are included within the shared database.

A few of the other benefits of blockchain are tv hat exchanges can be collab consequently by the creator without either party uncovering himself to the hazard. This permits 
"ver-delivery sus installment" to settle monetary exchanges utilizing the blockchain without trusted intermediaries.

\section{Method}

\subsection{Blockchain Drawbacks}

Let's assume that, after reviewing the above checklist, you have genuine prospects for using blockchain. Because database disintermediation will provide major business benefits. However, before concluding that a project is built on the blockchain [22], it is important to understand 2 drawbacks namely loss of confidentiality and reduced performance.

\subsection{Confidentiality}

Each hub within the blockchain freely confirms and forms exchanges, without depending on the suppositions of other hubs. Hubs do this since they have full permeability to (a) the current database, (b) the adjustments asked by exchanges, (c) rules overseeing substantial exchanges, and (d) advanced marks that demonstrate each transaction's root. It is without a doubt to construct the database, but the downside is that many applications, particularly budgetary, the total straightforwardness delighted in by each hub is an outright agreement [23].

A centrally built system will have no problems. although limiting certain transactions, the restriction is enforced in one central location. As a result, the complete database is visible only at that location, not across multiple nodes. at the authority center are usually asked to read the data, which can accept or reject them as you wish. Whereas a regular database is both readcontrolled and write-controlled, and the blockchain is author-controlled.

In reality, numerous techniques are accessible to diminish this issue. among them are straightforward thoughts, such as executing beneath the blockchain character or scrambling data that can as it was be seen by certain parties. For funds, the hub should approve installments without knowing all the points of interest. Topographic strategies such as exchange privileged insights and prove without information are being created, but they will not be examined here. In truth, the more data an accomplice needs to cover up on the blockchain, the heavier the computational burden it'll pay to create and confirm exchanges. No matter how innovation creates, they will never beat basic strategies and totally cover-up information in one trusted intermediary [24].

\subsection{Performance}

Happy Valentine The second disadvantage of blockchains is that they will always be slower than centralized databases. It's not just today, blockchain is slow due to new technology and hasn't been optimized yet, because that's the nature of the blockchain itself. When processing transactions, the blockchain must do all of the same, but carry 3 additional burdens.

1. Verify signature. Each blockchain exchange must be carefully marked by a cryptographypublic-private PHY conspire such as ECDSA. This can be imperative since exchanges spread between hubs like peer-to-peer, so their source cannot be demonstrated. Signature creation and confirmation are computationally calculated and they make a "bottleneck" on numerous blockchain stages. Once the connection is built up in a centralized database, there's no have to separately confirm each approaching request.

2. Consensus mechanism. In a contributing database such as the blockchain, there's an exertion to be made, specifically to guarantee that the hubs within the organize reach agreement. If it depends on a agreement component, it may include communication or exchanges with a brief delay in agreement ("Fork") and consequent resolution. On the other hand, centralized databases got to fight with strife and exchange invalidations, and they are moreover much less likely to have exchanges being lined and handled at one location.

3. Redundancy. Apart from the performance of individual nodes, what must be considered is the total amount of computation required by the blockchain. While the database processes are centralized for a single transaction (twice in a special setting), the trans-blockchain actions that must be processed independently by each network node. Therefore keep the database always updated. 


\subsection{Usage Templates}

If questions are asked about aside performance, they can look for solutions. Most blockchain uses use sufficient resources. From the experience of using blockchain applications, blockchain exchange centers and databases can be summarized as follows:

- Disintermediation, specifically blockchain empowers numerous parties who don't completely believe each other to share a single database and don't require mediators.

- Secret. That's, all blockchain individuals can see all exchanges taking put. Indeed if it employments different methods to stow away a few viewpoints of the activity. The blockchain will continuously have more data than a centralized database.

As such, blockchain is perfect for databases where each client can peruse everything but, no single party control is who can type in what. In differentiate, with a conventional database, a single substance gives control over all perused and type in operations, and its clients are subject to the wishes of that substance

When will this dedication support blockchain use? the approach to the question can use theoretical and empirical approaches. Hypothetically the center is on the key contrasts between blockchain and conventional databases and how these contrasts educate client conceivable outcomes [25]. Meanwhile, empirically, in this case with the category of realworld solutions being built by the Multichain platform, it is not surprising that if the focus is on theory or practice, the same categories emerge, including:

- Easy financial syste

- Tracking origin

- Records between organizations

- Multiparty aggregation

Here we examine 4 different uses of "light of core sacrifice". It explains why the benefits of medication outweigh the less confidential consumption.

\subsection{Lightweight Financial Systems}

Starting from the blockchain class and the applications most recognized and desired by a group of entities to regulate the financial system. In such a system, one or more assets will be scarce and are traded in the exchange between entities [26].

In arrange for the rare resource to stay, two related issues will be unraveled. The primary must guarantee that the records are the same as the resources and cannot be sent more in one put ("twofold spend"). At the moment, it must be impossible for anybody to make an unused unit of resources rapidly ("fraud"). Any substance can do something that can take boundless esteem from the framework [27].

A common arrangement to this issue is physical tokens, for illustration metal coins or printed on paper. These tokens unravel the double issue of investing since material science rules anticipate one token from entering two places at the same time. The issue of falsifying can be fathomed by making tokens that are exceptionally troublesome to deliver. In any case, physical tokens still have a few disadvantages that ordinarily make them "unreasonable".

- As a pure asset, physical tokens can be stolen without being able to trace them.

- Physical tokens are slow and expensive to move large amounts or over long distances.

- Cannot be faked

These insufficiencies may well be maintained a strategic distance from by leaving physical tokens and re-imagined possession of resources within the record and overseen by trusted middle people. Within the past, composed records were recorded on paper, and tended to be run on a normal database. Delivered intermediaries transfer ownership and modified in the ledger as a response to authenticated requests. unlike physical tokens, dubious transactions can be reversed quickly and easily.

However, the ledger is concentration control. It puts a lot of power in one place and creates significant security. If some things can hack into the database, they can change the ledger and steal other people's funds and destroy it. Worse, it can damage large SKU files, and attacks are harder to detect and prove. then, wherever we are going to use a centralized ledger, 
we invest significant time and money in mechanisms protecting the integrity of the ledger. Many cases require batch-based continuous verification between central ledgers [28].

The blockchain can be shared in the ledger, it provides benefits without concentration problems. Each substance runs a hub and keeps up a duplicate of the record and overall has total control over its possess resources and is ensured by a private watchword. spreader exchanges between hubs in a peer-to-peer design, whereas the blockchain guarantees a well-maintained agreement. The design does not take off a central point of assault, where programmers can degenerate the record substance of the record. And as a result, advanced monetary frameworks can be utilized more rapidly and cheaply, and with the included advantage of real-time compromise endeavors.

As examined, the drawback is that they utilize the record by looking at all the exchanges that take put, and make much required believe. Blockchain is apropos called a money related framework, where the financial stakes and the number of members and exchanges are moderately moos. In cases like these, secrecy can be an issue, indeed in case individuals pay consideration to what other individuals are doing, and they will learn a part almost esteem. And from there since the lower stakes will be able to maintain a strategic distance from the bother and cost of setting up a middle person (bank).

Cases of complex budgetary frameworks incorporate swarm subsidizing (subsidizing), blessing cards (blessing cards), dependability focuses (dependability focuses), and nearby money. More often than not, resources can be recovered in more than one put. In case we see a few blockchains utilized within the monetary segment, such as peer-to-peer trading between resource directors that are not specifically related to the application. Blockchain is being tried within the bookkeeping framework and must keep up control of stores. In that case, costs are lower and will diminish the contact from the blockchain in favor of the site's benefits as well as the potential misfortune of privacy isn't a major issue.

\subsection{Tracking Provenance}

Our second lesson frequently listens to almost all MultiChain clients following the seal and development of high-value products within the supply chain, such as shallots, pharmaceuticals, beauty care products, and gadgets. Other records such as a letter of credit. Most of these things are subject to fraud and theft. These issues can be fathomed utilizing the blockchain by When a tall esteem thing is made, a fitting advanced center token is issued by the substance, at that point confirms at the point of beginning. Computerized tokens are exchanged in parallel when physical things alter hands. at that point, the chain is reflected by a blockchain chain.

More often than not, tokens as virtual certificates of genuineness are much more troublesome to take or fashion. After sending an advanced token, the ultimate beneficiary of the physical thing, whether a bank, retailer, wholesaler, or client can track it all the way. In fact, in terms of documentation such as bills of filling, physical merchandise can be removed.

Even though all makes sense, the record peruser will see the database, say by thing producer, can accomplish the same assignment. The database can store proprietor records, acknowledge marked exchanges for each alter of possession, and react to demands related to current circumstances. Why utilize blockchain? since, for this sort of application, there's an advantage of conveyed belief. it doesn't matter with a centralized database. in case somebody alters with its substance, for illustration stamping a fake or stolen thing as honest to goodness, it can be followed by the blockchain. The substance can break the chain of guardianship. As a reward, distinctive tokens can be traded securely and right away, with the least blockchain level swap stage.

What about trust issues? The suitability of Blockchain for the supply chain is from a simple transaction pattern. Unlike the financial markets, most tokens move in one place, from origin to endpoint, by trading repeatedly. If competitors transact with each other, they cannot learn about each other's blockchain and relationships in the world. Then the activity can easily be partitioned into multiple ledgers, and each represents a different order or type of item.

\subsection{Interorganizational Record-Keeping}


The moment case within the past utilize is based on a tokenized resource, specifically: on-chain representation precluded things from being transferred between members. In any case, there's a moment bunch of blockchains that's related to resources. The chain capacities as a collective record-keeping instrument and makes all sorts of information which implies it can be monetary or bad habit versa.

One illustration is the basic communication review path between two or more organizations, for the case within the wellbeing care or lawful segment. No lawful organization or group can be trusted to preserve chronicled records since adulterated or erased data seem to harm others, even though everybody must concur with the substance of these files.

To unravel this issue, members require a shared database, and all composed records, with each record, went with by a timestamp and beginning of the prove. This arrangement will make a trusted middle person whose part is to gather and record information centrally. But blockchain will offer a distinctive approach, which is to provide organizations (bunches of individuals) to oversee these files together whereas anticipating untouchables from getting in and altering with them.

Blockchain applications are nothing new. Over the past 20 years, Z / Yen built a system whereby several entities collectively manage multiple digital audit trails. While those systems are not referred to as blockchain, they are technically identical in every way. It might be said that there is nothing new about using blockchain between organizations, it's just that the world will realize the possibilities.

In the actual data stored on the blockchain, there are three popular options:

- Unencrypted data. It can be studied by any blockchain member, giving full transcollective and prompt determination of debate cases.

- Encrypted data. It can be perused by the member agreeing to the portrayal key. In case of debate, anybody can uncover the key to a trusted specialist, such as a court, and utilize the blockchain to demonstrate the initial data.

- Hashed data. A "hash" acts as an advanced unique finger impression, speaking to sending commitments and a particular piece of information whereas putting away covered up information. Any party getting the information can effectively affirm whether it matches the hashed, but the finding of the information from the hash is computationally incomprehensible. As it were hashes are put on the blockchain. At that point, the first information is kept off-chain by interested parties, who can unveil it in case of a dispute. Initially, secrecy was not an issue for keeping records between organizations, as the point was to form a shared record that all members seem to do. Even though a few pieces of information is scrambled or characterized, in a few cases blockchain can offer assistance to oversee get to the privacy of off-chain information by providing digitally signed records. Another good thing about disintermediation is that no extra substance must be made and trusted to preserve records.

\subsection{Multiparty Aggregation}

In specialized terms, the blockchain utilization lesson is comparable to its past utilize in that numerous parties compose information onto collectively overseen records. In any case, the inspiration is to overcome the foundation issue of accumulating huge to discrete information , Imagine two banks with inner client character confirmation databases. At a few points, they will take note that there will be an expansive number of clients, so they enter a complementary sharing course of action where they relegate confirmation information to maintain a strategic distance from copies. The assertion is executed employing a master-slave data replication standard, that's, each bowl stores a duplicate that can as it was be examined specifically from another database and executes a parallel key against its claim database and its enigmatic records.

Envision if two banks welcomed three individuals to take part in this. Each of the five banks runs its claim ace database, at the side four reproductions examined from the others. With five aces and twenty copies, we have twenty-five add up to moment databases. And it can devour time and assets in any bank's IT department. 
20 banks rapidly shared data on this and looked at 400 fundamental illustrations. For 100 banks, up to 10,000 cases. In common, if individuals share data, the whole number of databases develops more than the number of participants. In a few of these forms, there's bound to be a framework that will break down and go down.

The self-evident arrangement is that all banks send information to trusted middle people, whose work is to gather information in an ace database. Each bank can inquiry the database remotely as well as run its possess local read copy. Whereas there's nothing off-base with this approach, blockchain offers a more designed elective to one in which databases are shared specifically by banks. Blockchain moreover brings the included advantage of redundancies to the framework as an entire.

It is exceptionally critical to clarify that blockchain does not as it acted as a database merchant like Cassandra7, MongoDB.8. Not at all like these frameworks, each blockchain hub implements rules to avoid members from adjusting erasing, or including information. But there's still disarray. Bru - as of late discharged blockchain stage can end up one hub carrying on improperly. On any occasion, a great stage will too make it simple to oversee a organize of thousands of hubs, either resound or exit if given the suitable permissions.

\section{Results and Discussion}

\subsection{Blockchains In Production}

It can be concluded from several cases where the blockchain was allowed to run on MultiChain which was used for production following version 1.0 in the summer of 2017. Each application has been described as being independently built by a third party and running on four or more nodes as well as several active validators [29]. Most importantly, every blockchain file deals with real business in problems that cannot be solved in ordinary databases.

\subsubsection{Workflow Management For Infrastructure Project}

Constructive may be a program company in Brazil. Pany builds arrangements for the plan and development of the key foundation, to be specific structure 9. Over the past 15 long times, the Construtivo Approach has a program as a benefit which implies the company acts as a trusted mediator center for overseeing venture information. As a rule, the conventional approach is to guarantee that everybody keeps a project's see of advance.

In arrange to fulfill client wants, they work out extraordinary straightforwardness and inspecting aptitudes. Constructive has presently coordinated the blockchain record into the arrangement, which gives the choice of setting up imperative on-chain information ventures alongside the Construtivo database. Most foundation ventures in South America are as of now utilizing this. Each extends has its possess chain, with Construtivo run hubs and partners, such as temporary workers and companies. Depending on the venture prerequisites, the chain can record plans, contracts, and workflow-related data, and member pants can investigate it employing a web interface.

The organization for this framework venture has 4 hubs, the normal exchange estimate is $15 \mathrm{~K}$. All of these hubs per chain take an interest within the approval handle, whereas control of client consents remains with Construtivo.

\subsubsection{Shared Ledger for a Catastrophe Bond}

Solidum Accomplices is a speculation advisor a sorry company that specializes in making catastrophe ties. These are monetary rebellious that pay speculators the next rate of return than conventional commercial bonds, but they carry the chance of as it were halfway or no installment if certain occasions happen. In substance, the buyer acts like a protections company, giving capital to cover misfortunes and make a profit.

To create exchanging simpler, non-physical securities such as bonds are customarily held by trusted mediators for sake of their proprietors. Exchanges are settled essentially through the upgrading of mediator records. For Solidium, the favored broker Euroclear holds more than $\$$ 30 trillion in monetary resources for sake of financial specialists or more than $10 \%$ of the world's add up to. Regularly, with 4,000 representatives 15 workplaces around the world, Euroclear does not give this benefit for free. Due to later changes, one of which was a keeping money 
accomplice, Solidium misplaced get to Euroclear and had to discover other ways to oversee the record. They will issue $\$ 15$ million specifically to the blockchain, besides dollar-denominatetokens that can be utilized to execute. In case they like, they will feature two coin or ICO advertising grants. Be that as it may, it encompasses a genuine basic resource and anticipated esteem for the future.

Blockchain permits for secure conveyance (exchanges), where two clients alter dollars and bonds in one step. A conventional accomplishment requires the assistance of a trusted mediator. Separated from dodging go-between expenses, blockchain grants give solidium with incredible ease and control for anyone who takes an interest within the system.

Each pool of members has their claim bond, which gives control over the on-chain resources. In the meantime, the gatekeeper knows the personality within the genuine world and each address on the blockchain. After doing anti-money washing, Solidum will grant clients get to the chain at that point they can execute with each other specifically. The arrange has 10 hubs and 4 of them are permanently online and take an interest within the agreement process.

\subsubsection{Transaction Notarization for E-Commerce}

Cryptologic, a blockchain consultancy based in Rosario, Argentina, has built and executed a framework for making e-commerce legal officials. This combination of exchanges could be a way to assist resolve disputes between buyers and dealers. They are, to begin with, client was MercadoLibre, the foremost well known e-dragon location, and has an assessed \$ 1 billion in income per year [30].

For the most part, when clients make records and purchase from online exchanges, they believe the dealer to record exchanges safely and for all time. In hone, no one erases or adjusts exchange records [31]. In case each exchange is recorded on a blockchain whose substance is open to the open and control is spread over a diverse number of parties, usually a record that troublesome to alter retroactively [32].

Keep up secrecy and exchange information hashed some time recently it is implanted within the chain. Hashes give an instrument for timestamping as well as their fiber note rising basically to resolve a debate in the event that either party uncovers a hash less exchange [33]. The arrange right now contains 7 lasting hubs spread over Cryptologic, different government workplaces, as well as abroad accomplices. Since exchanges contain hashes, their arrangement is obvious with the best speed of 50 activities per moment.

\section{Conclusions and Suggestions}

We provide an early example of the blockchain allowed in production. The network is small, and the transaction volume is well below the product limit. Therefore, it is important to carry out an analysis of several examples

Even so, the thing that catches the eye is what this app has in common. The most important thing is not to use blockchain, it all comes from a desire for decentralization. These three cases show that there are clear reasons for choosing a blockchain architecture through a centralized database or order. Furthermore, no chain has however been moved to a decentralized show for chairmen as well as those that bolster clients to give the authorization to execute. Such a thing must be seen from how frequently a decentralized government or organization (as backed by the MultiChain admin agreement demonstrates) is beneficial or not in the hone. Maybe it is adequately given by the blockchain in a straightforward way of all chairman action, whereas giving up control of this movement by one party.

As a result, the nature of this application is the view that blockchain could be a common reason for innovation and isn't limited to any specific industry. An imperative portion of media scope may be gotten by specialists in certain cases, such as interbred settlement, monetary supply chains, and shared personalities, but in reality, in the case of blockchain can be connected each client tries to maintain a strategic distance from the computerized framework control record.

\section{Reference}

[1] R. Sriwiji, "Studi Empiris Pada Pemodelan Dan Prediksi Harga Bitcoin berdasarkan 
Informasi Blockchain Menggunakan Bayesian Regularization Neural Network," 2019.

[2] N. Taliasih, "Implementasi Algoritma Kombinasi Rc4 Dan Base64 Untuk Mengamankan Database Klien Pt Infokes." Universitas Komputer Indonesia, 2019.

[3] I. A. Kurniawan, D. Yusman, and I. O. Aprilia, "Utilization of Blockchain Technology Revolution in Electronic ID Card Data Integrity," Aptisi Trans. Manag., vol. 5, no. 2, pp. 137-142, 2021.

[4] M. J. Sadeq, S. R. Kabir, M. Akter, R. Forhat, R. Haque, and M. Akhtaruzzaman, "Integration of Blockchain and Remote Database Access Protocol-Based Database," in Proceedings of Fifth International Congress on Information and Communication Technology, 2021, pp. 533-539.

[5] E. Guustaaf, U. Rahardja, Q. Aini, H. W. Maharani, and N. A. Santoso, "Blockchainbased Education Project," Aptisi Trans. Manag., vol. 5, no. 1, pp. 46-61, 2021.

[6] M. C. Nurfaizi, A. Bhawiyuga, and K. Amron, "Pengembangan Gateway untuk Menghubungkan Jaringan loT (Internet of Things) dan Jaringan Blockchain," J. Pengemb. Teknol. Inf. dan IImu Komput. e-ISSN, vol. 2548, p. 964X, 2020.

[7] R. Banach, "Blockchain applications beyond the cryptocurrency casino: The Punishment not Reward blockchain architecture," Concurr. Comput. Pract. Exp., vol. 33, no. 1, p. e5749, 2021.

[8] A. Urquhart, "The inefficiency of Bitcoin," Econ. Lett., vol. 148, pp. 80-82, 2016.

[9] B. Kurniawan, N. Nirwanto, and A. Firdiansjah, "The effect of service innovation on customer satisfaction indihome internet provider in central java through corporate reputation as variable intervening," Int. J. Sci. Technol. Res., vol. 8, no. 10, pp. 144-151, 2019.

[10] F. Glaser, "Pervasive decentralisation of digital infrastructures: a framework for blockchain enabled system and use case analysis," 2017.

[11] S. Nathan, C. Govindarajan, A. Saraf, M. Sethi, and P. Jayachandran, "Blockchain meets database: Design and implementation of a blockchain relational database," arXiv Prepr. arXiv1903.01919, 2019.

[12] A. Z. Ausop and E. S. N. Aulia, "Teknologi Cryptocurrency Bitcoin Dalam Transaksi Bisnis Menurut Syariat Islam,” J. Sosioteknologi, vol. 17, no. 1, pp. 74-92, 2018.

[13] F. Agustin, F. P. Oganda, N. Lutfiani, and E. P. Harahap, "Manajemen Pembelajaran Daring Menggunakan Education Smart Courses," TMJ (Technomedia Journal) Vol. 5 No. 1 Agustus 2020, p. 40, 2021.

[14] F. Agustin, S. Syafnidawati, N. P. L. Santoso, and O. G. Amrikhasanah, "Blockchainbased Decentralized Distribution Management in E-Journals," Aptisi Trans. Manag., vol. 4, no. 2, pp. 107-113, 2020.

[15] M. U. Noor, "IMPLEMENTASI BLOCKCHAIN DI DUNIA KEARSIPAN: PELUANG, TANTANGAN, SOLUSI, ATAU MASALAH BARU?," Khizanah al-Hikmah J. IImu Perpustakaan, Informasi, dan Kearsipan, vol. 8, no. 1, pp. 86-96, 2020.

[16] Q. Aini, A. Alwiyah, and D. M. Putri, "Effectiveness of Installment Payment Management Using Recurring Scheduling to Cashier Performance," Aptisi Trans. Manag., vol. 3, no. 1, pp. 13-21, 2019.

[17] Z. Fauziah, H. Latifah, U. Rahardja, N. Lutfiani, and A. Mardiansyah, "Designing Student Attendance Information Systems Web-Based," Aptisi Trans. Technopreneursh., vol. 3, no. 1, pp. 23-31, 2021.

[18] S. Kosasi, "Karakteristik Blockchain Teknologi Dalam Pengembangan Edukasi," ADI Bisnis Digit. Interdisiplin J., vol. 1, no. 1, pp. 87-94, 2020.

[19] A. Adiyanto and R. Febrianto, "Authentication Of Transaction Process In E-marketplace Based On Blockchain?? technology," Aptisi Trans. Technopreneursh., vol. 2, no. 1, pp. 68-74, 2020.

[20] D. E. O'Leary, "Configuring blockchain architectures for transaction information in blockchain consortiums: The case of accounting and supply chain systems," Intell. Syst. Accounting, Financ. Manag., vol. 24, no. 4, pp. 138-147, 2017.

[21] M. G. Wibisono, "KETIDAKMAMPUAN INDONESIA DALAM MEMANFAATKAN BITCOIN DAN CRYPTOCURRENCY," Transform. Glob., vol. 6, no. 1, 2020.

[22] P. Edastama, N. Lutfiani, Q. Aini, S. Purnama, and I. Y. Annisa, "Blockchain Encryption 
on Student Academic Transcripts using a Smart Contract," J. Educ. Sci. Technol., 2021.

[23] A. Jivanyan, "Lelantus: Towards Confidentiality and Anonymity of Blockchain Transactions from Standard Assumptions.," IACR Cryptol. ePrint Arch., vol. 2019, p. 373, 2019.

[24] T. T. Thwin and S. Vasupongayya, "Blockchain based secret-data sharing model for personal health record system," in 2018 5th International Conference on Advanced Informatics: Concept Theory and Applications (ICAICTA), 2018, pp. 196-201.

[25] M. Suryana and A. Rahman, "Geospatial retrieval hotel syari'ah berbasis practical byzantine fault tolerance blockchain untuk meningkatkan keamanan data." UIN Sunan Ampel Surabaya, 2021.

[26] K. Budiarta, S. O. Ginting, and J. Simarmata, Ekonomi dan Bisnis Digital. Yayasan Kita Menulis, 2020.

[27] S. Aggarwal, R. Chaudhary, G. S. Aujla, N. Kumar, K.-K. R. Choo, and A. Y. Zomaya, "Blockchain for smart communities: Applications, challenges and opportunities," J. Netw. Comput. Appl., vol. 144, pp. 13-48, 2019.

[28] T. Aste, P. Tasca, and T. Di Matteo, "Blockchain technologies: The foreseeable impact on society and industry," Computer (Long. Beach. Calif)., vol. 50, no. 9, pp. 18-28, 2017.

[29] M. Ali, J. Nelson, R. Shea, and M. J. Freedman, "Blockstack: A global naming and storage system secured by blockchains," in 2016 \{USENIX\} annual technical conference (\{USENIX\}\{ATC\} 16), 2016, pp. 181-194.

[30] R. M. H. Thamrin, E. P. Harahap, A. Khoirunisa, A. Faturahman, and K. Zelina, "Blockchain-based Land Certificate Management in Indonesia," ADI J. Recent Innov., vol. 2, no. 2, pp. 232-252, 2021.

[31] J. Leonard, D. Damanik, and O. Amirkhasanah, "Application of Information Session Information System as Media Submission of Final Results Comprehensive Session," J. Recent Innov., vol. 1, no. 1, pp. 62-70, 2020.

[32] Z. Fauziah and D. Supriyanti, "Influence of Business Process Maturity Model as a Business Architecture Planning Proposal," ADI J. Recent Innov., vol. 2, no. 2, pp. 253263, 2021.

[33] X. Min, Q. Li, L. Liu, and L. Cui, "A permissioned blockchain framework for supporting instant transaction and dynamic block size," in 2016 IEEE Trustcom/BigDataSE/ISPA, 2016, pp. 90-96. 